\title{
Entscheid der Paritätischen Interpretationskommission
}

TARMED Suisse

\author{
Nummer: 04043 \\ Gültig ab: 26. Oktober 2004 \\ Titel: Aktenstudium \\ Kapitel: 00.01.01, 02.01 \\ Tarifpositionen: 00.0140, 02.0070 \\ Problemstellung
}

Unter welchen Voraussetzungen darf das Aktenstudium mit den Tarifpositionen «Ärztliche Leistung in Abwesenheit des Patienten» verrechnet werden?

\section{Décision de la Commission d'interprétation paritaire}

TARMED Suisse

Numéro de la question: 04043

Date: 26 octobre 2004

Titre: Etude de dossier

Chapitre: 00.01.01, 02.01

Position tarifaire: 00.0140, 02.0070

Teneur de la question

Dans quelles conditions les positions tarifaires «Prestations médicales en l'absence du patient/de la patiente» peuvent-elles être facturées pour l'étude du dossier?

\section{Beschluss}

Als Aktenstudium gilt das patientenbezogene Studium von Fremdakten (Lesen und Beurteilung ausführlicher fremder Akten, also nicht das Lesen der selbst verfassten Krankengeschichte des Patienten) inkl. Studium dort zitierter Literaturstellen. Begründete Ausnahmen für das extensive Aufarbeiten von Eigenakten sind vorbehalten. Dies ist zu dokumentieren und dem Kostenträger auf Anfrage zur Verfügung zu stellen.

\section{Décision}

Vaut comme étude du dossier: l'étude de documents étrangers relatifs au patient (lecture et évaluation de documents détaillés étrangers et non pas de ceux rédigés par le médecin et figurant déjà dans le dossier médical du patient), y compris l'étude des articles de référence y cités. Demeure réservée comme exception motivée l'étude restreinte de ses propres documents. Ceci doit être documenté et mis à la disposition de l'assureur à sa demande. 